University of Nebraska - Lincoln

DigitalCommons@University of Nebraska - Lincoln

Faculty Publications from the Harold W. Manter Laboratory of Parasitology

8-1-1992

\title{
Parasites As Probes for Biodiversity
}

Scott Lyell Gardner

University of Nebraska - Lincoln, slg@unl.edu

Mariel L. Campbell

University of New Mexico, campbell@sevilleta.unm.edu

Follow this and additional works at: https://digitalcommons.unl.edu/parasitologyfacpubs

Part of the Parasitology Commons

Gardner, Scott Lyell and Campbell, Mariel L., "Parasites As Probes for Biodiversity" (1992). Faculty Publications from the Harold W. Manter Laboratory of Parasitology. 26.

https://digitalcommons.unl.edu/parasitologyfacpubs/26

This Article is brought to you for free and open access by the Parasitology, Harold W. Manter Laboratory of at DigitalCommons@University of Nebraska - Lincoln. It has been accepted for inclusion in Faculty Publications from the Harold W. Manter Laboratory of Parasitology by an authorized administrator of DigitalCommons@University of Nebraska - Lincoln. 


\title{
PARASITES AS PROBES FOR BIODIVERSITY*
}

\author{
Scott L. Gardner and Mariel L. Campbell \\ Department of Nematology, The University of California, Davis, Davis, California 95616-8668
}

ABSTRACT: Cestodes of the genus Linstowia, parasitic in marsupials, show patterns of coevolution and ancient historical-ecological connections. Correlated with the breakup of the austral landmasses (Gondwanaland) of the Neotropical and Australian regions from the Antarctic continent, the age of this host-parasite community is estimated to be between 60 and 70 million years old. Based on the data from the survey of parasites of mammals from throughout Bolivia and from the phylogenetic analysis of the cestodes, we urge the planners of biodiversity preserves in the neotropics to consider the Yungas of Bolivia as a region that supports an ancient ecological community worthy of consideration as a biopreserve.

There has been an increasing awareness by the general public and by the scientific community of the accelerating loss of biological diversity in both temperate and tropical habitats (Anonymous, 1989). This is manifested in part by the recent creation of specific funding for biotic surveys and inventories by the United States $\mathrm{Na}$ tional Science Foundation and by increased research in biodiversity especially in tropical rain forest habitats (Mares, 1992; Yates and Estes, 1992). In addition, the National Science Board of the United States (NSB) has recently recommended the completion of a global biological inventory. The NSB (Anonymous, 1989) stated: "This is urgent; without a reversal in current rates of habitat destruction and species extinction, a comprehensive systematic survey will be possible only for the next 10 to 20 years."

Much of the current interest in the study and preservation of diversity in the tropics stems from calls of alarm that were directly stimulated by 2 factors: estimates of the number of species of insects occurring in trees of neotropical rain forests and estimates of the number of square-kilometers of rain forests that are being cleared annually (Anonymous, 1989; Ehrlich and Wilson, 1991; Erwin, 1991).

In this light, recent effort in research in biodiversity and conservation has been focussed on developing methods of making decisions as to which geographic areas should be included in preserves or bioreserves (Erwin, 1991; Morowitz, 1991; Soulé, 1991). There has been recent criticism of the emphasis on conservation of

Received 29 October 1991; revised 6 April 1992; accepted 7 April 1992.

* Paper from the von Ihering Centenary Symposium on parasite biogeography and coevolution presented at the 1991 annual meeting of the American Society of Parasitologists. tropical rain forest habitats at the (potential) expense of such activities in other types of habitats that support diverse faunas such as mammals (Mares, 1992).

Herein we present a method that provides qualitative estimates of biodiversity by examining the parasite fauna (and thus inferred ecological relationships) of selected groups of mammals in the central part of Bolivia. We use the general methods of historical ecology as developed by Brooks (Brooks, 1985; see also Brooks and McLennan, 1991) to examine the patterns of phylogeny and ecology of cestodes from small marsupials in Bolivia. These studies have allowed us to estimate the maximum age of a hostparasite ecological community in the region of the Yungas and the ecotone of the Chaco in the eastern Andean foothills of central and southern Bolivia (Fig. 1). The cestode parasites of these marsupials serve as indicators of old ecological associations that also may signify the presence of diverse communities of organisms that have evolved and coexisted over very long periods of time.

Cestodes of the genus Linstowia Zschokke, 1899 (Cestoda: Anoplocephalidae) occur in marsupials in the neotropics and in marsupials and monotremes in Australia (Beveridge, 1983; Gardner and Campbell, 1992). The first linstowiid to be described from mammals in Australia was Linstowia semoni (Zschokke, 1896) from Isoodon obesulus (Shaw) (Marsupialia: Peramelidae). In about 1903, von Ihering, working out of Sao Paulo, Brazil, sent specimens of an undescribed species of cestode to Fritz von Zschokke in Basel, Switzerland. From this material, taken from Peramys americanum (=Monodelphis americana (Muller)), Zschokke (1904a, 1904b) described a new cestode and named it Linstowia iheringi in honor of von Ihering. With the exception of a redescription of $L$. iheringi by Gomes 
TABLE I. Character states of South American and Australian Linstowia and outgroups (2 species of Oochoristica). Numbers in table represent character states $(0$ or 1 are binary; and $0,1,2$, or higher represent multistate characters).

\begin{tabular}{|c|c|c|c|c|c|c|c|c|c|c|c|c|c|c|c|c|c|}
\hline \multirow[b]{2}{*}{ Species of cestodes } & \multicolumn{17}{|c|}{ Characters* } \\
\hline & 1 & 2 & 3 & 4 & 5 & 6 & 7 & 8 & 9 & 10 & 11 & 12 & 13 & 14 & 15 & 16 & 17 \\
\hline Linstowia macrouri & 1 & 0 & 0 & 1 & 0 & 0 & 1 & 0 & 0 & 2 & 1 & 0 & 0 & 1 & 1 & 4 & 0 \\
\hline Linstowia echidnae & 1 & 0 & 0 & 1 & 0 & 1 & 1 & 1 & 0 & 2 & 2 & 0 & 0 & 1 & 1 & 5 & 2 \\
\hline Linstowia iheringi & 1 & 1 & 1 & 1 & 1 & 0 & 0 & 2 & 1 & 1 & 1 & 1 & 0 & 1 & 1 & 3 & 1 \\
\hline Linstowia semoni & 1 & 0 & 0 & 1 & 0 & 1 & 0 & 0 & 0 & 1 & 2 & 1 & 1 & 0 & 1 & 4 & 2 \\
\hline Linstowia schmidti & 1 & 1 & 1 & 1 & 1 & 0 & 0 & 1 & 0 & 0 & 0 & 1 & 2 & 1 & 1 & 0 & 3 \\
\hline Linstowia sp. $†$ & 1 & 1 & 1 & 1 & 1 & 0 & 0 & 1 & 1 & 0 & 0 & 1 & 2 & 1 & 1 & 1 & 3 \\
\hline Oochoristica eremophila $\ddagger$ & 0 & 0 & 0 & 0 & 0 & 0 & 0 & 2 & 0 & 1 & 0 & 1 & 2 & 2 & 0 & 1 & 1 \\
\hline Oochoristica antechini & 0 & 0 & 0 & 0 & 1 & 0 & 0 & 0 & 0 & 1 & 0 & 1 & 0 & 1 & 1 & 2 & 0 \\
\hline
\end{tabular}

* Definition of characters of 6 species of Linstowia and 2 species of Oochoristica: 1, Position of excretory and genital ducts; 2, form of scolex; 3 , orientation of suckers; 4 , presence or absence of sucker pockets; 5 , anastomosing excretory ducts; 6 , relative length of cirrus sac; 7 , lateral expansion of vitelline gland; 8, relative development of egg capsules; 9 , distribution of eggs in gravid segments; 10 , number of testes; 11 , number of segments; 12 , extent of confluence of Mehlis' and vitelline glands; 13, length-width ratio of gravid segments; 14, dorsal-ventral positional development of uterus and ovary; 15 , presence or absence of seminal receptacle; 16 , total length; 17, maximum width of strobila.

$\dagger$ Undescribed species of Linstowia.

$\ddagger$ Designated outgroups.

(1979), almost $75 \mathrm{yr}$ passed from the time of the original description of $L$. iheringi to the present with no further work on the neotropical linstowiids.

\section{MATERIALS AND METHODS}

During the past $6 \mathrm{yr}$, small mammals including some in the genera Thylamys and Monodelphis have been collected by us from several ecologically and geologically distinct regions of Bolivia (Unzueta, 1975). Collections of mammals were made from throughout lowland and highland Bolivia. In all cases, mammals were examined for the presence of parasitic helminths and most were sampled for the presence of coccidia in their feces.

Methods of collection and preparation of mammals and their parasites follow Gardner (1991) and Gardner and Campbell (1992). The phylogenetic relationships of the species of cestodes considered in this study were estimated from the analysis of 17 morphological characters of which 8 were multistate and 9 were binary (Table I).

The computer program PAUP 2.4.1 (Swofford, 1985) was used to generate phylogenetic hypotheses by numerical cladistic analysis. Outgroup analysis (see Brooks and McLennan, 1991) was used to root trees and polarize characters. Two species of cestodes of the genus Oochoristica (O. antechini Beveridge, 1977, and O. eremophila Beveridge, 1977) were chosen as outgroups, and data on characters for both species were taken from Beveridge (1977).

\section{RESULTS AND DISCUSSION}

Collections of marsupials from throughout Bolivia conducted from 1984 to the present revealed that cestodes of the genus Linstowia occur only in hosts restricted in their distribution to a relatively small area in the Chaco thorn forest of Bolivia and in the Yungas region (Andean foot- hills) at the western margin of the Chaco (Fig. 1 and see Unzueta, 1975). The Chaco is characterized as a semideciduous forested habitat with an extreme dry winter and a wet summer (Unzueta, 1975). Sarmiento (1976) presented evidence that the Chaco region may be one of the oldest extant ecosystems in South America, and Brown (1982) indicated that the Yungas of Bolivia had a high probability of serving as a paleoecological forest refuge.

We performed a phylogenetic analysis on 5 described and 1 undescribed species of Linstowia (see Beveridge, 1983; Gardner and Campbell, 1992) using 2 species of Oochoristica Lühe as outgroups to the linstowiids. Three trees were produced with identical consensus indexes of which an Adams consensus tree is shown (Fig. 2). Two primary clades of Linstowia are represented: 1 clade with 3 species occurring in South American didelphoid marsupials with the other (also with 3 species) found in Australian marsupials and 1 monotreme (Beveridge, 1983).

The cladogram (Fig. 2) shows a transpacific or austral separation between species of Linstowia occurring in marsupials and a monotreme in Australia and the clade with 3 species from neotropical marsupials. The austral transpacific distribution of these cestodes is similar to that described for Nothofagus and podonomine and diamesine midges (see Humphries and Parenti [1986] for a review).

Cestodes similar to species of the genus Oochoristica may have given rise to linstowiids now extant in marsupials in both Australia and South America, and Beveridge (1983) proposed this hy- 


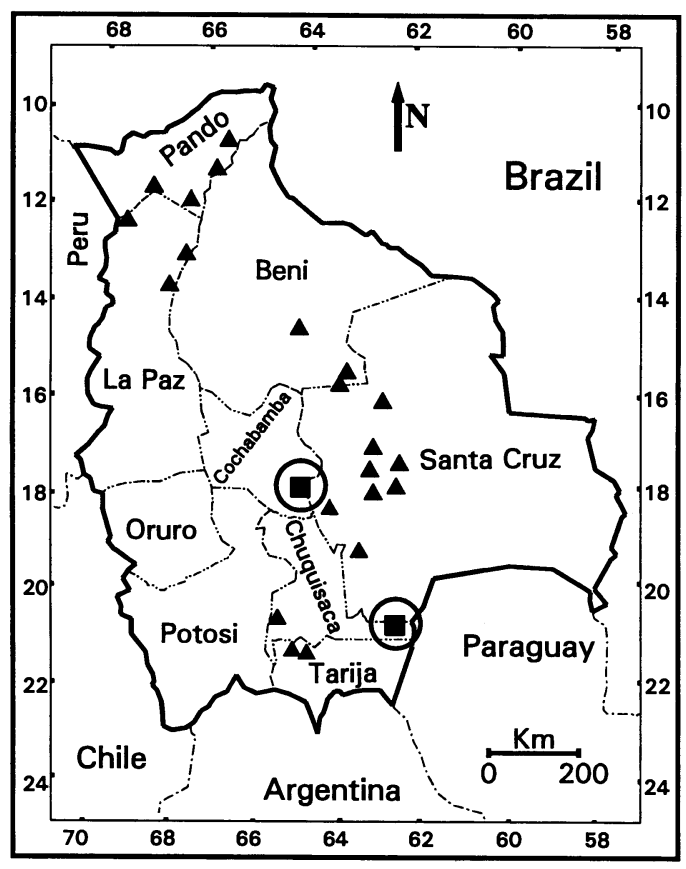

FIGURE 1. Map of Bolivia showing the general localities of marsupials collected from 1984 to the present. Triangles indicate collections of marsupials without Linstowia and squares with circles mark areas where marsupials were collected that were infected with $\mathrm{Lin}$ stowia.

pothesis. Morphological divergence of marsupials in the Neotropical and Australian regions has obscured phylogenetic relationships based on morphology; however, Reig et al. (1987) provided some evidence that the microbiotheriids may have been the direct ancestors of presently extant Australian and neotropical marsupials.

Our data allow us to present the hypothesis that the extant cestode-marsupial-intermediate host community existed before the separation of the biota that was present on the southern continents of Australia, Antarctica, and South America. Microbiotheriids with an austral distribution must have been associated with these cestodes before the complete breakup of Gondwanaland. Our data also fail to reject the hypotheses of Sarmiento (1976) and Brown (1982) that the Yungas-Chaco ecotone is a relatively old area that has been ecologically stable for a long period of geological time.

Cestodes of the genus Linstowia occur in hosts with limited geographic distributions in eastern Australia, eastern New Guinea, an isolated area in the eastern foothills of the Andes in Bolivia, and in an area in eastern Brazil that is not yet

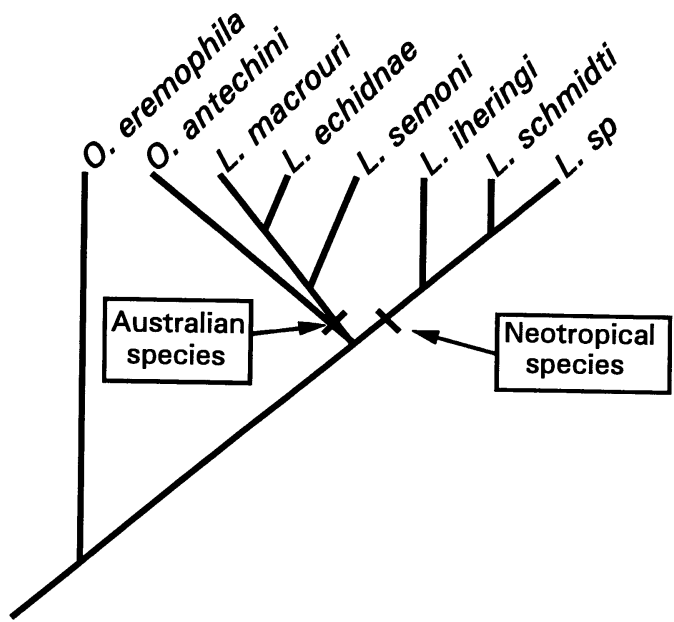

FIGURE 2. Cladogram of species of Linstowia from Australia and South America (length $=36$, consistency index $=78 \%$ ). Table I contains matrix and definitions of characters used in constructing the tree. Perpendicular lines highlight the separate evolutionary paths of the 2 groups of Linstowia after the breakup of the southern continents.

characterized ecologically (Zschokke, 1904a, 1904b). Based on the generally estimated times of divergence of the microbiotherioid marsupials that are thought to have given rise to both South American and Australian marsupials, a conservative estimate for the age of the last disjunction of this host-parasite ecological association can be set between the end of the Cretaceous period and the early Eocene epoch, around 60-70 million years ago (Reig et al., 1987; Gardner and Campbell, 1992).

Several strategies have been proposed for conservation of biotic diversity (Soulé, 1991) and numerous papers have recently appeared on the subject (e.g., Wilson, 1986; Ehrlich and Wilson, 1991; Erwin, 1991; Morowitz, 1991; Soulé, 1991). Present estimates of total biotic diversity on the earth range from 30 million to 100 million species, and human-caused extinctions are estimated to be continuing at exponential rates (Ehrlich and Wilson, 1991; Soulé, 1991). Precise cataloging of existing diversity to the level of the species continues to slow due to the decrease in number of trained scientists capable of collecting and describing new species.

Phylogenetic methods can provide direct estimates of the historical aspects of ecology (Brooks, 1985). In the present case, we combine indirect estimates of diversity (i.e., evolutionary ecology) with direct estimates of the history of 
the organisms in an area, i.e., historical ecology sensu Brooks (1985).

During field research, collection of a definitive host (in this case, a mammal) infected with parasites known to utilize arthropods as intermediate hosts provides much more information relative to contemporary ecological associations than if only the host were considered without regard to the parasite fauna. Thus, collecting a mammal infected with parasites with heteroxenous life cycles provides data on both the definitive host and components of the host-parasite community. In the present case, the life cycle of the cestodes (Linstowia) includes infection of the intermediate host by metacestodes (from ingestion of eggs in feces of the marsupial) and reingestion of the intermediate host by small opossums of the genera Thylamys and Monodelphis. Some of the same classes of intermediate hosts can be predicted to have been present before the divergence of the continental land masses, and these intermediate hosts currently remain in ecological association with marsupial hosts in the areas of eastern Australia, eastern New Guinea, and the limited areas of the Yungas and Chaco of southeastern Bolivia.

Decisions concerning which areas to establish as biotic preserves are difficult. In many areas, necessary baseline data on distribution of species over geographic space are unavailable. It is only through biological surveys that data such as these are obtained. By combining biological survey information with a phylogenetic analysis of the parasites of a group of hosts, areas of Bolivia that may be ecologically and geologically old can be predicted.

Lacking from the current literature on biodiversity and conservation biology are robust methods of making decisions on which areas to conserve. May (1990) and Vane-Wright et al. (1991) provided some relatively unbiased indexes of taxonomic distinctness of organisms based on cladogram topology. Erwin (1991) discussed another method in which a cladogram is produced, and then the areas of occurrence of each species are matched with the tips of the cladogram. Brooks (1985) provided a method that already has been shown to be robust; here a cladogram of a group of organisms is prepared, then ecological characters of the groups in question are mapped directly onto the tree. With this type of study, areas of maximum taxonomic and ecological diversity can be predicted (Brooks and McLennan, 1991).
The cestodes discussed here occurring in marsupials in Bolivia represent phylogenetic relicts sensu Brooks and Bandoni (1988). The geographic region where this host-parasite community occurs represents an ecologically ancient area in which hosts and their parasites must have been associated for some 60 million years. Thus, we present 2 levels of justification for establishing a biotic preserve in the Yungas-Chaco region of Bolivia: a phylogenetic analysis of cestodes that establishes clear historical-ecological connections between the southern land masses and the presence of a complex community of mammals, parasites, and associated intermediate hosts in a relatively small area in the Yungas-Chaco ecotone. At the very least, our analyses indicate that more detailed biotic surveys should be conducted in the Chaco and Yungas regions before final decisions are made regarding placement of national preserves in Bolivia.

Comparative tests using parasites as indicators of ecological age and diversity (i.e., probes for biodiversity) will come as more complete studies of biotic diversity in different geographic areas of the earth become available.

\section{ACKNOWLEDGMENTS}

We thank the discussants and presenters at the von Ihering Centenary Symposium for ideas related to this topic. We also thank Dan Brooks for encouraging us to produce this paper and for the idea of using the term "probe" for the use of parasites as indicators of biodiversity. This work was supported in part by NSF grants BSR9024816 and BSR-8408923.

\section{LITERATURE CITED}

ANONYMOUS. 1989. Loss of biological diversity: A global crisis requiring international solutions. A report to the National Science Board/Committee on International Sciences Task Force on Global Biodiversity. National Science Foundation, Washington, D.C., 19 p.

BeVERIDGE, I. 1977. On two new linstowiid cestodes from Australian dasyurid marsupials. Journal of Helminthology 51: 31-40.

. 1983. The genus Linstowia Zschokke, 1899 (Cestoda: Anoplocephalidae) in Australian mammals with the description of a new species. Systematic Parasitology 5: 291-304.

Brooks, D. R. 1985. Historical ecology: A new approach to studying the evolution of ecological associations. Annals of the Missouri Botanical Garden 72: 660-680.

, AND S. M. BANDONI. 1988. Coevolution and relicts. Systematic Zoology 37: 19-33.

- ANd D. A. McLennan. 1991. Phylogeny, ecology, and behavior: A research program in 
comparative biology. University of Chicago Press, Chicago, 434 p.

Brown, K. S., JR. 1982. Paleoecology and regional patterns of evolution in neotropical forest butterflies. In Biological diversification in the tropics, G. T. Prance (ed.). Columbia University Press, New York, p. 255-308.

Ehrlich, P. R., AND E. O. Wilson. 1991. Biodiversity studies: Science and policy. Science 253: 758761 .

ERwIN, T. L. 1991. An evolutionary basis for conservation strategies. Science 253: 750-751.

Gardner, S. L. 1991. Phyletic coevolution between subterranean rodents of the genus Ctenomys (Rodentia: Hystricognathi) and nematodes of the genus Paraspidodera (Heterakoidea: Aspidoderidae) in the neotropics: Temporal and evolutionary implications. Zoological Journal of the Linnean Society of London 102: 169-201.

- AND M. L. CAMPBell. 1992. A new species of Linstowia Zschokke, 1899 (Cestoda: Anoplocephalidae) from marsupials in Bolivia with comments on the biogeography of cestodes of the genus Linstowia. Journal of Parasitology 78: (in press).

GoMEs, D. C. 1979. Contribuicao ao conhecimento dos helmintos parasitos de marsupiasis no Brasil, da colecao helmintologica do Instituto Oswaldo Cruz (Cestoda, Archiacanthocephala e Linguatulida). Revista Iberica de Parasitologica 39: 587599.

Humphries, C. J., ANd L. R. PARenti. 1986. Cladistic biogeography. Clarendon Press, Oxford, p. 59-71.

MARES, M. A. 1992. Neotropical mammals and the myth of Amazonian biodiversity. Science 255: 976979.

MAY, R. E. 1990. Taxonomy as destiny. Nature 347: 129-130.

Morowitz, H. J. 1991. Balancing species preservation and economic considerations. Science 253: $752-753$.
Reig, O. A., J. A. KIrsch, AND L. G. Marshall. 1987. Systematic relationships of the living and neocenozoic American "oppossum-like" marsupials (suborder Didelphimorphia), with comments on the classification of these and of the cretaceous and paleogene new world and European metatherians. In Possums and opossums: Studies in evolution, Vol. 1, M. Archer (ed.). Surrey Beatty and Sons, Pty Ltd., New South Wales, p. 1-89.

SARMIENTO, G. 1976. Evolution of arid vegetation in tropical America. In Evolution of desert biotas, D. W. Goodall (ed.). University of Texas Press, Austin, p. 65-99.

Soulé, M. E. 1991. Conservation: Tactics for a constant crisis. Science 253: 744-749.

SwOFFORD, D. L. 1985. PAUP-Phylogenetic analysis using parsimony, Version 2.4.1. Illinois Natural History Survey, Champaign, Illinois (software).

UnZUETA, O. Q. 1975. Mapa ecologicao de Bolivia. Ministerio de Asuntos Campesinos y Agropecuarios, La Paz, Bolivia, 312 p.

VANe-Wright, R. E., C. J. HuMPhries, AND R. J. WiLLIAMS. 1991. What to protect-Systematics and the agony of choice. Biological Conservation 55: 235-254.

Wilson, E. O. 1986. The current state of biological diversity. In Biodiversity, E. O. Wilson (ed.). National Academy Press, Washington, D.C., p. 3-18.

YATES, T. L., AND J. R. Estes. 1992. Support for biodiversity research at the National Science Foundation. Canadian Biodiversity 1: (in press).

ZsCHOKKE, F. 1904a. 2. Die Cestoden des südamerikanischen Beuteltiere. Zoologischer Anzeiger 27: 290-293.

- 1904b. Die Darmcestoden des amerikanischen Beuteltiere. Centralblatt für Bakteriologie, Parasitenkunde und Infektionskrankheiten 36: 51-62. 